\title{
Non-small cell lung carcinoma in an adolescent manifested by acute paraplegia due to spinal metastases: a case report
}

\author{
Ulrike Ackert ${ }^{1}$, Dieter Haffner ${ }^{1,2}$ and Carl Friedrich Classen ${ }^{1 *}$
}

\begin{abstract}
Introduction: Bronchial carcinomas in childhood and adolescence are extremely rare; only individual cases have been reported previously.

Case presentation: We report on a 16-year-old Caucasian German boy with non-small cell lung carcinoma (squamous cell non-small cell lung carcinoma) stage IV, T4N2M1, without epidermal growth factor receptor overexpression and/or mutation or k-ras mutation. He presented with paraplegia due to spinal metastases of the bronchial carcinoma. No familial predisposition or toxin exposure was identified. Treatment following adult protocols consisted of surgical intervention for spinal metastases, first-line cisplatinum and gemcitabine, irradiation and second-line docetaxel. After a transient response our patient experienced disease progression and died about 10 months later.
\end{abstract}

Conclusion: Response and survival in our 16-year-old patient were similar to adult patients with stage IV non-small cell lung carcinoma.

\section{Introduction}

Lung cancer is the leading cause of cancer-related mortality in adults in many countries, especially in smokers $[1,2]$. There are small cell and non-small cell lung cancers (NSCLC). NSCLC are subdivided into adenocarcinomas (about 50\%), squamous cell (about 20\%), large cell (about 10\%), and otherwise not defined carcinomas [1]. The TNM staging system is closely associated with prognosis. Metastatic disease, defined as stage IV, accounting for $10 \%$ to $20 \%$ of cases, has a median survival time of nine months and a five-year survival of about $1 \%$ [2]. The peak age for NSCLC is 50 years to 60 years [2]. Recently, several molecular characteristics of NSCLC, including p53 mutations, epidermal growth factor receptor (EGFR) mutations with subsequent dysregulation of the ras/raf kinase pathway and k-ras mutations, have been defined [3], leading to some targeted therapy approaches. Their benefit is still not quite clear $[4,5]$.

\footnotetext{
* Correspondence: cfclassen@gmx.de

'University Children's Hospital Rostock, Ernst-Heydemann-Strasse 8, D-18057 Rostock, Germany

Full list of author information is available at the end of the article
}

The therapy options-surgery, chemotherapy, irradiation and targeted therapy-are usually applied according to the TMN staging and the molecular signature [3-5]. Tumors should be resected primarily whenever possible [6]. Unresectable tumors imply a palliative condition. Combination first-line chemotherapy is used to obtain maximum efficacy, eventually combined with radiotherapy. In second-line treatment, monotherapy is proposed for patients in an appropriately good condition $[4,6]$.

For first-line therapy, cisplatinum-based chemotherapy plus radiotherapy is superior to radiotherapy or chemotherapy alone [6,7]. Several agents have been applied in addition to cisplatinum, for example paclitaxel, docetaxel, gemcitabine, pemetrexed, vinorelbine and irinotecan. Gemcitabine is regarded as first choice in squamous cell carcinomas by most authors [7]. For second-line therapy, monotherapy, for example with docetaxel, is common. Usually, an aggressive therapy would now be inappropriate [7].

In the last years, targeted therapies have shown antitumoral effects. Most targets are related to EGFR or the raf/ras kinase signaling, since deregulation of this pathway is common in NSCLC [3,7]. Both EGFR-targeted
C Biomed Central

() 2011 Ackert et al; licensee BioMed Central Ltd. This is an Open Access article distributed under the terms of the Creative Commons Attribution License (http://creativecommons.org/licenses/by/2.0), which permits unrestricted use, distribution, and reproduction in any medium, provided the original work is properly cited. 
antibodies, for example cetuximab, and kinase inhibitors, like erlotinib, have a low toxicity, however, their efficacy depends on the signaling pathway deregulation $[3,7]$. Antibodies against the vascular-endothelial growth factor receptor (VEGFR) are efficient in non-squamous cell tumors [1].

Lung carcinomas in patients below 20 years of age are extremely rare. Here, we report the case of a 16-yearold boy with a non-small cell, squamous cell bronchial carcinoma T4N2M1 initially presenting with paraplegia due to spinal metastases. In spite of all therapeutic measures performed according to adult treatment protocols our patient experienced only a transient response, followed by disease progression, and died about nine and half months after diagnosis.

\section{Case presentation}

Our patient was the second child of non-consanguineous healthy parents, both Caucasian (ethnically German); his sister was healthy. Three cases of carcinomas, including a bronchial carcinoma, had been observed in grandparents and an aunt.

He was born after an uneventful pregnancy and showed normal development except for mild attention deficit disorder. He never smoked nor abused other substances, nor was he exposed to tobacco smoke, chemicals or irradiating toxins.

At the age of 16 years, eight weeks before initial presentation, he experienced an episode of back pain followed four weeks later by unproductive cough with minimal hematoptysis. A chest X-ray showed a discrete central infiltrate. Two weeks before admission he had several episodes of back pain. Finally, the boy had experienced a numb feeling in the lower body half from about thoracic vertebra (Th) seven downwards, loss of strength and insecure gait for two days prior to admission. Pain sensitivity and tendon reflexes were preserved. Strength was grade four in his legs and feet. A sharpened breath murmur of amphoric type was heard. Otherwise, the boy was in a stable condition with a normal examination status.

Magnetic resonance imaging (MRI) of his spine, followed by computed tomography (CT) of his chest (Figures 1 and 2) showed an acute transverse myelocompression at Th5 by a tumor with intraspinal extensions, and a central intrapulmonary lesion infiltrating both main bronchi. An emergency laminectomy with subtotal tumor resection was performed with stabilization by a fixateur interne. A histological analysis showed a non-small cell squamous bronchial carcinoma (NSCLC), EGFR amplification and kras mutation negative. Staging included a bronchoscopy with biopsy of an intrabronchial tumor portion, a bone scan, MRI and CT. An inoperable lung tumor, with metastases at Th5 and in his os sacrum and left scapula, was

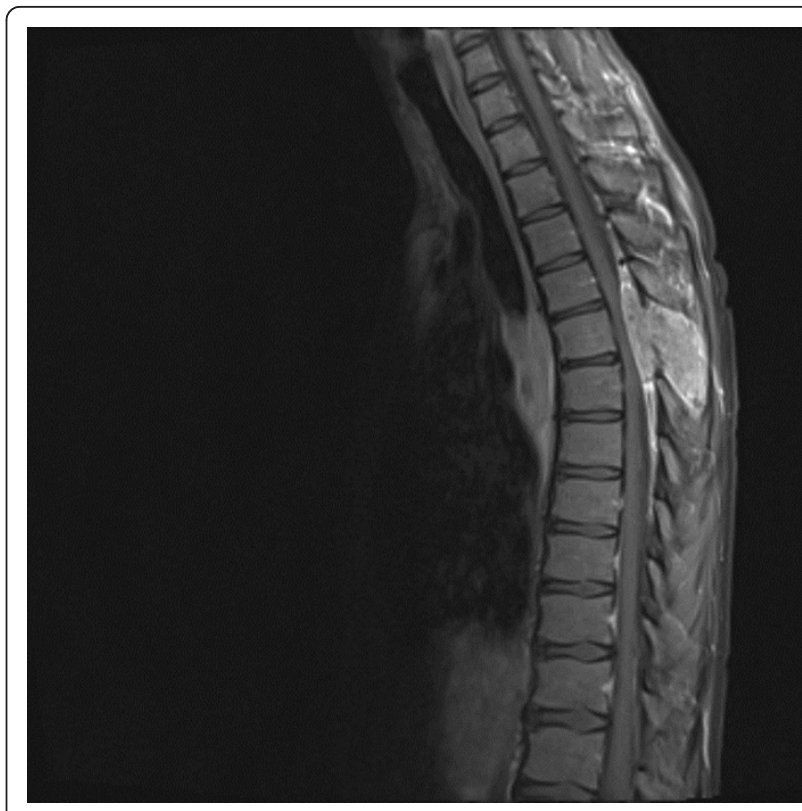

Figure $1 \mathrm{MRI}$ of the thoracic spine, in sagittal view, T1weighed image with contrast medium enhancement. The tumor leads to significant myelocompression, and grows infiltratingly into the surrounding tissue.

diagnosed, in other words, stage IV, T4N2M1. A familiar p53 mutation and a germ cell tumor were excluded. Complete laboratory and clinical workup showed no infections, immunodeficiency or drug addiction.

Treatment was initiated according to current recommendations for adults. Six cycles of intravenous

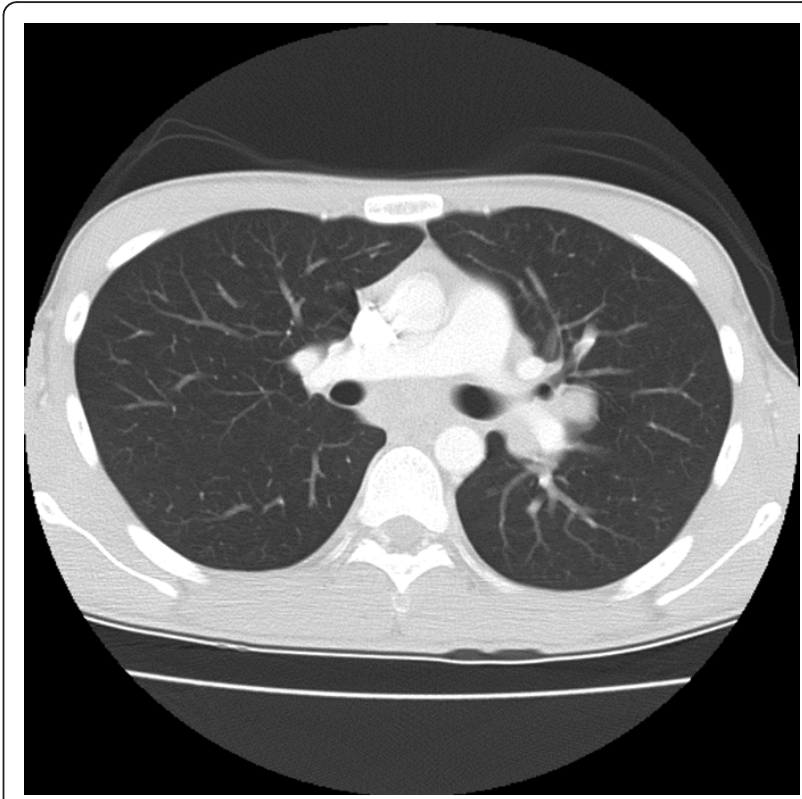

Figure 2 CT scan of his lungs, showing a large central space occupying lesion surrounding both main bronchi. 
cisplatinum $\left(70 \mathrm{mg} / \mathrm{m}^{2} / \mathrm{d}\right.$, day one) and gemcitabine $\left(1000 \mathrm{mg} / \mathrm{m}^{2} / \mathrm{d}\right.$, day one and day eight) were given three-weekly, with a bisphosphonate (pamidronate, 30 mg) every four weeks. New generation EGFR or signaling inhibitors were not applied since k-ras mutation and EGFR overexpression and/or mutation were negative.

After four weeks, local progression of the sacral metastasis led to ischial nerve irritation requiring extended analgetic medication (opioids plus pregabalin). Fractionated sacral irradiation with 30 Gy soon induced analgesia. Clinical tumor progress at Th5 developed at about three months, confirmed by MRI, which led to neurosurgical resection of a regrown metastasis. Since it was not feasible to separate irradiation of the main bronchial tumor and the area of Th5, combined fractionated irradiation with 30 Gy was subsequently performed.

Toxicity of the six cycles of cisplatinum and gemcitabine over the first four months following diagnosis con-

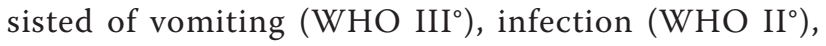
tricytopenia (WHO III ${ }^{\circ}$ ) and cachexia (WHO III ${ }^{\circ}$ ), requiring home parenteral nutrition.

Now, a chest CT scan showed shrinkage of the main bronchial tumor but also appearance of pleural lesions, likely to represent metastases. Thus it appeared inappropriate to proceed with gemcitabine and cisplatinum, since our patient wanted a less toxic therapy.

In accordance with recommendations for second-line therapy in adults, the boy received docetaxel $(75 \mathrm{mg} /$ $\mathrm{m}^{2} / \mathrm{d}$ every three weeks) as monotherapy for four and a half months after diagnosis. However, disease progression developed one month later with new spinal metastases at Th12, L1, L2 and L4. Another course of palliative irradiation was given for analgesia. Besides cachexia, the boy suffered from febrile chills and cough and a pleural effusion. About seven months after diagnosis, chemotherapy was discontinued to preserve quality of life as much as possible.

About eight months after diagnosis, the boy presented with double vision, headache and diabetes insipidus. A $\mathrm{CT}$ scan of his head revealed numerous brain metastases. Palliative dexamethasone was initiated.

Further multimodal palliative care was provided and our patient lived until about nine and a half months after diagnosis and died at home.

\section{Discussion}

Since 1876, when McAldowie first described a case of lung cancer in a five-month-old child [8], the disease has only occasionally been reported in children and adolescents. Published series include different histological entities including carcinoids, mucoepidermoid carcinomas, inflammatory pseudotumors, and others; only a minority are squamous cell carcinomas [9-11]. In 1977 and 2003, two series of 24 and 92 patients, respectively, with lung cancer below 40 years were published, with only one patient below 20 years in each. Their prognosis was similar to that of older patients [12,13]. Analyzing 26 patients below 30 years, Mizushima et al. [14] found a more favorable prognosis in the young patients, however, there was a low incidence of squamous cell carcinoma and a predominance of stage I.

The largest series of pediatric lung cancer was collected in a 1983 meta-analysis [15]. In 151 malignant lung tumors, beside many carcinoids and lymphomas, 47 were bronchogenic carcinomas, including six squamous cell tumors.

In conclusion, the published literature on pediatric squamous NSCLC is too sparse to draw any clear conclusion as compared with the older population.

In our case, several questions remain unanswered. First, why did the boy develop the disease in the first place? Neither the analysis of the tumor itself, nor the anamnestic or clinical workup gave any indication as to cause; in particular, no toxin exposure, immunodeficiency or familial disposition could be identified.

The second question is whether the exceptionally young age of our patient was associated with any special disease features. We found that histology, genetics, distribution, type of response and time course of the disease were similar to what is observed in older patients. Finally, it has to be asked whether any other treatment options might have been effective in our patient. More than six cycles of cisplatinum and gemcitabine chemotherapy in combination with irradiation, as first-line standard therapy for NSCLC patients, are rarely tolerated. Equally, the irradiation given as palliative focal treatment of painful bone metastases followed by tumor field irradiation after tumor shrinkage by initial chemotherapy represent a common approach in adults. So it may only be speculated whether further addition of a targeted drug might have been beneficial. Randomized studies indicate that drugs targeting the EGFR or $\mathrm{ras} / \mathrm{raf}$ kinase pathway are only effective in cases with deregulation of these pathways [3]. Other treatment modalities or strategies that might have helped the boy do not, to our best knowledge, exist.

\section{Conclusion}

Taken together, in the case reported here, we observed a stage IV NSCLC in a 16-year-old boy, in which the course of the disease was as may be expected in typical cases contracting the disease at an older age.

\section{Consent}

Written informed consent was obtained from the mother (legal guardian) of our patient for publication of this case report and any accompanying images. A copy of the written consent is available for review by the Editor-in-Chief of this journal. 


\section{Acknowledgements}

The authors gratefully acknowledge the permission by Prof. Hauenstein, Radiolology Clinic, University of Rostock, to use the images.

\section{Author details}

'University Children's Hospital Rostock, Ernst-Heydemann-Strasse 8, D-18057 Rostock, Germany. ${ }^{2}$ Department of Pediatric Kidney, Liver, and Metabolic Diseases, Hannover Medical School, Carl-Neuberg-Strasse 1, D-30625 Hannover, Germany.

\section{Authors' contributions}

UA analyzed and interpreted the patient data regarding the clinical presentation. DH added particular background information and was a major contributor in writing the manuscript. CFC performed basic organization of the writing and clinical data collection. All authors read and approved the final manuscript.

\section{Competing interests}

The authors declare that they have no competing interests.

Received: 23 May 2011 Accepted: 28 September 2011 Published: 28 September 2011

\section{References}

1. Stinchcombe TE, Socinski MA: Current treatments for advanced stage non-small cell lung cancer. Proc Am Thorac Soc 2009, 6:233-241.

2. Younes RN, Schutz FA, Gross JL: Preoperative and pathological staging of NSCLC: retrospective analysis of 291 cases. Rev Assoc Med Bras 2010 56:237-241.

3. Adjei AA: K-ras as a target for lung cancer therapy. J Thorac Oncol 2008, 6(Suppl 2):S160-S163.

4. Mirshahidi HR, Hsueh CT: Updates in non-small cell lung cancer-insights from the 2009 45th annual meeting of the American Society of Clinical Oncology. J Hematol Oncol 2010, 3:18.

5. Tsim S, O'Dowd CA, Milroy R, Davidson S: Staging of non-small cell lung cancer (NSCLC): a review. Respir Med 2010, 104:1767-1774.

6. Mantovani C, Novello S, Ragona R, Beltramo G, Giglioli FR, Ricardi U: Chemo-radiotherapy in lung cancer: state of the art with focus on the elderly population. Ann Oncol 2006, 17(Suppl 2):ii61-63.

7. Gewanter RM, Rosenzweig KE, Chang JY, Decker R, Dubey S, Kong FM Lally BE, Langer CJ, Lee HK, Movsas B: ACR Appropriateness Criteria: nonsurgical treatment for non-small-cell lung cancer: good performance status/definitive intent. Curr Probl Cancer 2010, 34:228-249.

8. McAldowie AM: Primary cancer of the lungs in a child five and a half months old. Lancet 1876, 2:570.

9. Bellah RD, Mahboubi S, Berdon WE: Malignant endobronchial lesions of adolescence. Pediatr Radiol 1992, 22:563-567.

10. Hancock BJ, Di Lorenzo M, Youssef S, Yazbeck S, Marcotte JE, Collin PP: Childhood primary pulmonary neoplasms. J Pediatr Surg 1993, 28:1133-1136.

11. Lal DR, Clark I, Shalkow J, Downey RJ, Shorter NA, Klimstra DS, La Quaglia MP: Primary epithelial lung malignancies in the pediatric population. Pediatr Blood Cancer 2005, 45:683-686.

12. Putnam JS: Lung carcinoma in young adults. JAMA 1977, 238:35-36.

13. Tian DL, Liu HX, Zhang L, Yin HN, Hu YX, Zhao HR, Chen DY, Han LB, Li Y, Li HW: Surgery for young patients with lung cancer. Lung Cancer 2003, 42:215-220.

14. Mizushima $Y$, Yokoyama A, Ito M, Manabe $H$, Hirai T, Minami $H$, Anzai $Y$, Sato H, Kusajima Y, Yamashita R, Kobayashi K, Sugiyama S, Kobayashi M: Lung carcinoma in patients age younger than 30 years. Cancer 1999, 85:1730-1733.

15. Hartman GE, Shochat SJ: Primary pulmonary neoplasms of childhood: a review. Ann Thorac Surg 1983, 36:108-119.

doi:10.1186/1752-1947-5-486

Cite this article as: Ackert et al: Non-small cell lung carcinoma in an adolescent manifested by acute paraplegia due to spinal metastases: a case report. Journal of Medical Case Reports 2011 5:486.

\section{Submit your next manuscript to BioMed Central and take full advantage of:}

- Convenient online submission

- Thorough peer review

- No space constraints or color figure charges

- Immediate publication on acceptance

- Inclusion in PubMed, CAS, Scopus and Google Scholar

- Research which is freely available for redistribution

Submit your manuscript at www.biomedcentral.com/submit 